\title{
RESEARCH ON FORCE AND MODAL ANALYSIS OF THE CANTILEVER ROOF MODEL OF A STADIUM
}

\author{
Qian Zhang, and Bairu Lu and Bei Jia \\ Xi 'an Eurasia university, School of Architecture And Engineering, xi 'an, shaanxi, 710065, China; \\ zhangqian1@eurasia.edu
}

\begin{abstract}
The large-span roof structure is favored by architects and structural engineers all over the world for its novel architectural shape and reasonable structural characteristics. It has been widely used in large public buildings such as sports buildings, memorial buildings and cultural buildings. Based on the structure design of the fourth national college students' competition winning entries for the model, this paper introduces the stadium upper cantilever roof structure model selection, process design, interface, etc. Using the finite element software ANSYS to analyze the model structure under different load conditions of the static performance, we acquire its natural frequency. The results show that the model meets both the strength and stiffness requirement.
\end{abstract}

\section{KEYWORDS}

Roof structure, Static analysis, Modal analysis, Strength

\section{INTRODUCTION}

The large-span roof structure is favored by architects and structural engineers all over the world for its novel architectural shape and reasonable structural characteristics. It has been widely used in large public buildings such as sports buildings, memorial buildings and cultural buildings $[1,2]$. The national college student structural design competition aims to cultivate students' innovation consciousness, team work and engineering practice ability. The students will organically combine the learning and the need together which will effectively raise the quality of innovative talent training. The competition of the titled is upper stadium cantilever roof structure design. We use the method of combining the theoretical analysis and experimental research together to conduct the structure model selection and determine the component section. With the finite element design software to analysis the force and modal, we can optimize the production process according to the analysis results so as to ensure the overall stability of the structure.

\section{MODEL DESIGN}

\section{Model overview}

According to the requirements of the structural design competition, we designed the cantilevered roof model of the stadium, with the column height of $200 \mathrm{~mm}$. The base of which is triangular and the top of which is quadrilateral. Cantilever girder is triangular with a cantilever length of $600 \mathrm{~mm}$, as shown in Figure 1. The model structure is made of wood, and the surrounding material is made of cloth paper. The mechanical properties are shown in Table 1. 


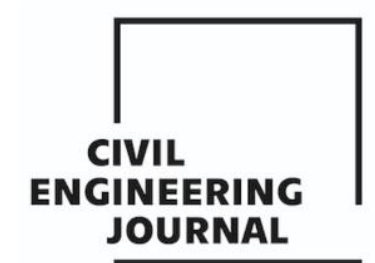

Article no. 52
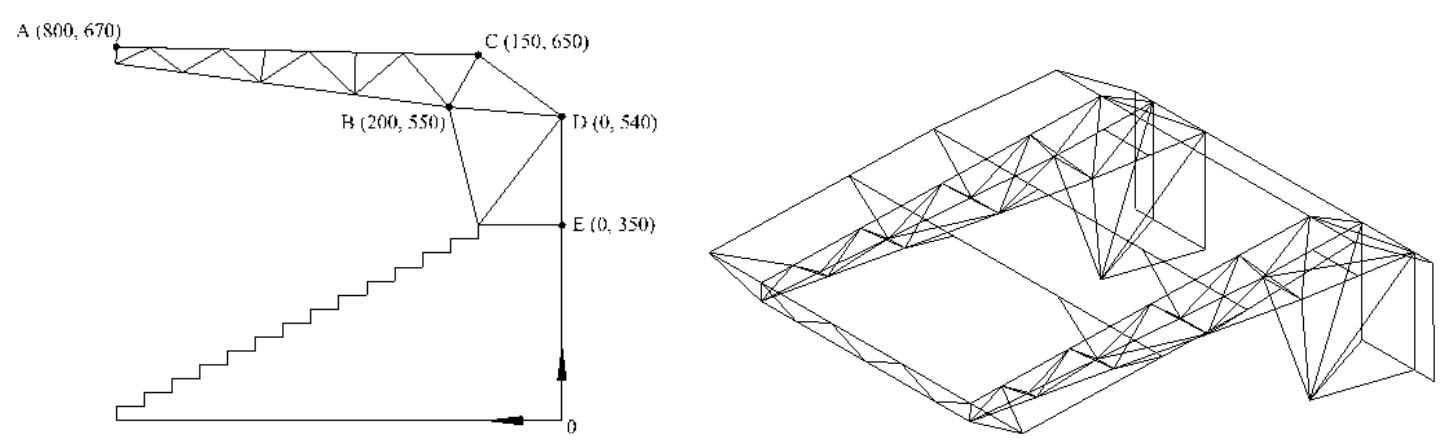

Fig. 1 - Schematic diagram of the model:

Tab. 1: Mechanical properties of wood

\begin{tabular}{|c|c|c|c|c|c|}
\hline $\begin{array}{c}\text { Name of the } \\
\text { material }\end{array}$ & $\begin{array}{c}\text { Elastic modulus } \\
(\mathrm{MPa})\end{array}$ & $\begin{array}{c}\text { Poisson's } \\
\text { ratio }\end{array}$ & $\begin{array}{c}\text { Density } \\
\left(\mathrm{kg} / \mathrm{m}^{3}\right)\end{array}$ & $\begin{array}{c}\text { Tensile } \\
\text { strength } \\
(\mathrm{MPa})\end{array}$ & $\begin{array}{c}\text { Compressive } \\
\text { stress } \\
(\mathrm{MPa})\end{array}$ \\
\hline wood & $1.0 \times 10^{4}$ & 0.3 & 283 & 30 & 19 \\
\hline
\end{tabular}

By analyzing the mechanical characteristics, the advantages and disadvantages of various stadium roof systems, and referring to a large number of classic stadiums around the world, the model design scheme was finally determined after repeated theoretical analysis, optimization and comparison. In other words, the cantilever roof structure of truss stadium was adopted as shown in Figure 2.

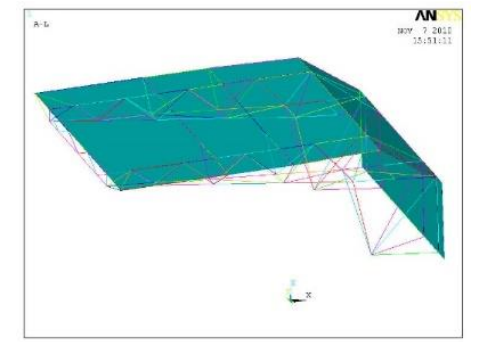

Fig. 2 - Truss type of the stadium roof structure

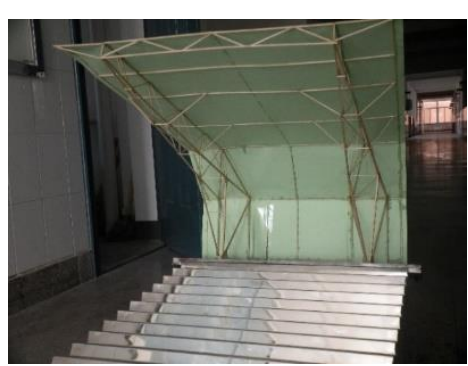

Fig. 3 - Model

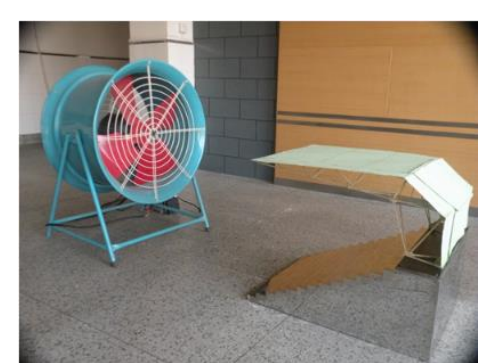

Fig. 4 - Model test

\section{Selection of the section}

In the process of model making, we adhere to the design idea of "clear concept, reasonable innovation, clear force, reliable structure", and comprehensively consider the mechanical properties of wood, the feasibility of model making, the appearance of model facade as well as the overall effect and other factors.

By combining theoretical analysis and experimental study together, we compared the mechanical and deformation properties of hollow section column and solid section column, and then finally determined the form of cantilever section. The model is shown in Figure 3 , and the model test is shown in Figure 4. The vertical column adopts the combination of two spatial quadrangles, each limb adopting the wooden rod with rectangular section. The upper chord of the cantilever girder adopts the "T" shape wood, the lower chord adopts the "L" shape angle wood and the abdomen pole adopts the square wood and rectangular rod. The detailed section is shown in Table 2. 
Tab. 2 - Section size details

\begin{tabular}{|c|c|c|c|c|c|}
\hline $\begin{array}{c}\text { Cross } \\
\text { Section type }\end{array}$ & $\begin{array}{c}\text { Wooden pole } \\
\text { with rectangular } \\
\text { section }\end{array}$ & $\begin{array}{c}\text { "T" type of } \\
\text { wood }\end{array}$ & $\begin{array}{c}\text { "L" type } \\
\text { Angle of } \\
\text { wood }\end{array}$ & $\begin{array}{c}\text { Square } \\
\text { wood }\end{array}$ & $\begin{array}{c}\text { Rectangular } \\
\text { wood }\end{array}$ \\
\hline $\begin{array}{c}\text { Section size } \\
(\mathrm{mm})\end{array}$ & &
\end{tabular}

\section{Model structure diagram}

See Figure 5 for the plan and elevation of the model, and Figure 6 for the 3D effect of the model. See Table3 for the model materials and details.

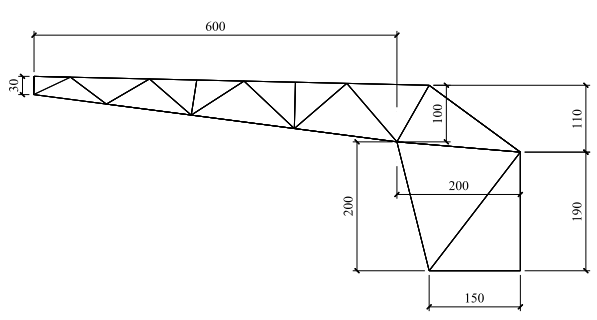

Fig. 5 - Front elevation and top view of the model (unit in the Figure: $\mathrm{mm}$ )

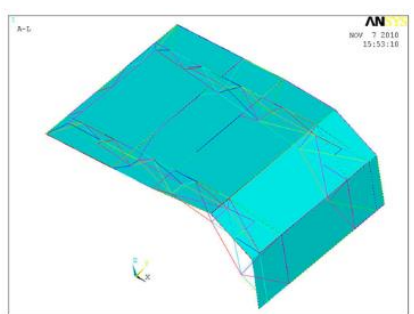

Fig. 6 - 3D rendering of the model

\section{FORCE ANALYSIS OF THE MODEL}

\section{Load analysis}

The model is mainly subjected to two kinds of loads, namely, gravity load and variable wind load.

\section{Gravity load}

The gravity load of the model includes the dead weight of component and the dead weight of cloth paper.

\section{Wind load}

Wind load is the main variable load of the cantilever roof structure for the main stadium, which is the important parameter for the structural design and the architectural dressing design. However, the domestic research on the wind pressure distribution and wind load prediction of this kind of structure is not sufficient. Therefore, it is necessary to put forward a simple and reasonable wind load calculation method for the structure design and the covering design of this structure ${ }^{[3]}$.

In the study of dynamic wind loads on roofs, one of the purposes is to study the possible critical frequency range of fluctuating wind. Near the critical frequency, the dynamic load is very large, and the roof stiffness should not be too low in the design, so as to avoid the design wind at the roof height reaching the critical wind $[4,5]$. The critical wind speed is calculated by the following formula.

$$
\bar{v}_{h c r}=\frac{n_{1} h}{s_{t}}
$$


Tab. 3 - Model material and detail dimension Table

\begin{tabular}{|c|c|c|c|c|c|c|c|}
\hline $\begin{array}{c}\text { Component } \\
\text { name }\end{array}$ & $\begin{array}{c}\text { Serial } \\
\text { number }\end{array}$ & Section size & Number & $\begin{array}{c}\text { Component } \\
\text { name }\end{array}$ & $\begin{array}{c}\text { Serial } \\
\text { number }\end{array}$ & $\begin{array}{l}\text { Section } \\
\text { size }\end{array}$ & Number \\
\hline \multirow{4}{*}{$\begin{array}{c}\text { Vertical and } \\
\text { horizontal } \\
\text { bars at the } \\
\text { top of the } \\
\text { roof }\end{array}$} & (1) & $2 \times 2 \times 650$ & 3 & \multirow{8}{*}{$\begin{array}{l}\text { Lower } \\
\text { compression } \\
\text { bar }\end{array}$} & 25 & $2 \times 2 \times 36$ & 2 \\
\hline & (2) & $2 \times 4 \times 650$ & 2 & & 26 & $2 \times 2 \times 58$ & 2 \\
\hline & (3) & $2 \times 2 \times 600$ & 1 & & 27 & $2 \times 2 \times 79$ & 2 \\
\hline & (4) & $2 \times 2 \times 580$ & 4 & & 28 & $2 \times 2 \times 9.6$ & 2 \\
\hline \multirow{17}{*}{$\begin{array}{c}\text { Diagonal tie } \\
\text { bar }\end{array}$} & (5) & $2 \times 4 \times 30$ & 2 & & 29 & $2 \times 2 \times 156$ & 2 \\
\hline & (6) & $2 \times 2 \times 7.8$ & 6 & & 30 & $2 \times 2 \times 179$ & 2 \\
\hline & (7) & $2 \times 2 \times 10.3$ & 2 & & 31 & $2 \times 2 \times 183$ & 2 \\
\hline & (8) & $2 \times 2 \times 410$ & 1 & & 32 & $2 \times 4 \times 218$ & 2 \\
\hline & (9) & $2 \times 2 \times 6.8$ & 2 & \multirow{3}{*}{ Column } & 33 & $4 \times 6 \times 218$ & 4 \\
\hline & (10) & $2 \times 2 \times 7.7$ & 4 & & 34 & $4 \times 6 \times 227$ & 4 \\
\hline & 11 & $2 \times 2 \times 8.6$ & 4 & & 35 & $2 \times 2 \times 195$ & 8 \\
\hline & 12 & $2 \times 2 \times 9.5$ & 4 & \multirow{4}{*}{ Base } & 36 & $2 \times 6 \times 162$ & 4 \\
\hline & 13 & $2 \times 2 \times 10.9$ & 4 & & 37 & $2 \times 6 \times 100$ & 2 \\
\hline & 14 & $2 \times 2 \times 11.5$ & 4 & & 38 & $2 \times 4 \times 30$ & 4 \\
\hline & 15 & $2 \times 2 \times 12.6$ & 4 & & 39 & $2 \times 6 \times 86$ & 2 \\
\hline & 16 & $2 \times 2 \times 12.3$ & 4 & \multirow{7}{*}{ Tail } & 40 & $2 \times 2 \times 403$ & 1 \\
\hline & 17 & $2 \times 2 \times 13.4$ & 4 & & 41 & $2 \times 2 \times 320$ & 3 \\
\hline & 18 & $2 \times 2 \times 14.3$ & 4 & & 42 & $2 \times 2 \times 300$ & 1 \\
\hline & 19 & $2 \times 4 \times 12.8$ & 4 & & 43 & $2 \times 2 \times 230$ & 1 \\
\hline & 20 & $2 \times 4 \times 19.1$ & 4 & & 44 & $2 \times 2 \times 239$ & 2 \\
\hline & 21 & $2 \times 4 \times 15.2$ & 2 & & 45 & $2 \times 2 \times 185$ & 1 \\
\hline \multirow{3}{*}{$\begin{array}{c}\text { lower } \\
\text { compression } \\
\text { bar }\end{array}$} & 22 & $2 \times 4 \times 810$ & 4 & & 46 & $2 \times 2 \times 192$ & 2 \\
\hline & 23 & $2 \times 2 \times 565$ & 4 & \multirow[b]{2}{*}{ Purlin } & 47 & $1 \times 2 \times 1050$ & 2 \\
\hline & 24 & $2 \times 2 \times 15$ & 2 & & 48 & $2 \times 2 \times 35$ & 4 \\
\hline
\end{tabular}

Where $n_{1}$ is the first natural vibration frequency $(\mathrm{Hz})$ of the roof, $h$ is the ground clearance height (m) of the leading edge of the roof, and $s_{t}$ is the Strouhal number.

Wind load on the cantilever roof of the grandstand comes from a very high negative pressure applied on the upper surface of the roof lip. The negative pressure is caused by the fluctuating pressure of the reattached shear layer. Under the action of the wind the response of cantilever roof is the combination of the random low frequency responses, which comprises a fluctuating pressure distribution due to shedding of the reattached shear layer at the roof tip, and a resonant response. The resonance response is induced by the first vibration mode of the roof. The load of resonance response is determined by the distribution of inertial load [6-8], and the pressure distribution of the low-frequency response can be derived by the quasi-steady method. For the mass per unit length and linear mode, the distribution is shown in Figure 7. 
Fig. 7 - Schematic diagram of calculated wind pressure distribution of roof

The equivalent design wind load with triangular distribution is adopted to calculate the common load in China.

$$
\begin{aligned}
& w_{h e}=\xi \mu_{h} w_{0} \\
& \xi=1.45+0.40\left[\frac{\bar{v}_{h} T_{1}}{L}-0.73\right]
\end{aligned}
$$

Where, $w_{h e}$ is the maximum value of triangular load on the leading edge of roof surface $\left(\mathrm{kN} / \mathrm{m}^{2}\right) ; \xi$ is the dynamic discharge corresponding to the first frequency of roof; $\mu_{h}$ is the variation coefficient of wind load at the height of roof; $w_{0}$ is the basic wind pressure $\left(\mathrm{kN} / \mathrm{m}^{2}\right)$. The symbol $\bar{v}_{h}$ and $L$ represent the average wind speed at the height of the roof, the cantilever length of the roof respectively. $T_{1}$ represents the first natural vibration period of the roof structure.

\section{Force analysis of stadium roof structure}

When designing the stadium roof, it is necessary to consider whether the load strength of the structure meets the requirement of static strength under various working conditions. The stress distribution and displacement distribution of roof structure can be obtained through analyzing under various loading conditions, which provides reliable analysis basis for roof design.

The finite element model was established based on the data of the designed model as shown in Figure 8 . The bearing capacity and displacement of stadium roof under three load conditions were checked as follows:

(1) load condition 1: roof dead weight $+1.88 \mathrm{~kg}$ heavy load steel bar

The displacement diagram, axial stress diagram, bending stress diagram and other effect diagram of the structure under this working condition are shown in Figures 9-13.

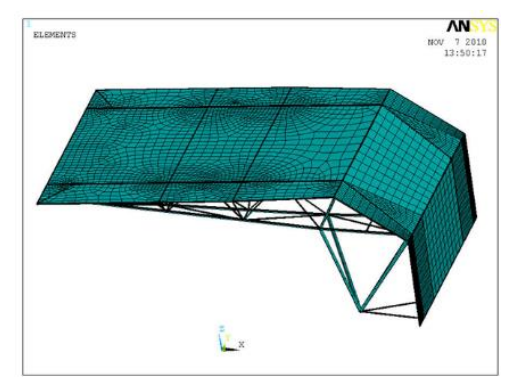

Fig. 8 - Finite element model of roof structure

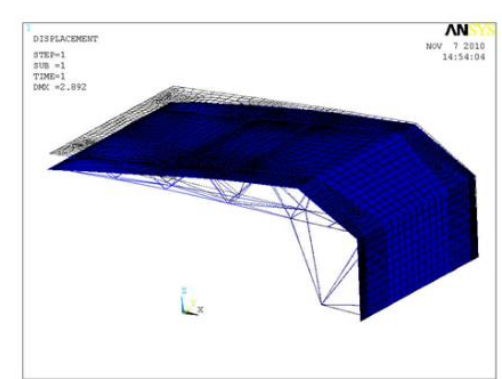

Fig. 9 - Deformation diagram in $\mathrm{Z}$ direction

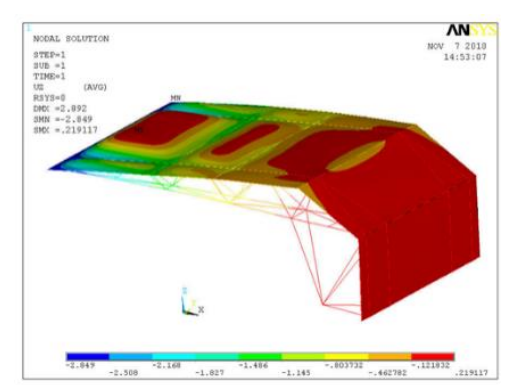

Fig. 10 - Displacement diagram in $\mathrm{Z}$ direction 


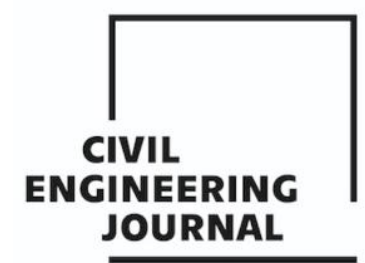

Article no. 52

THE CIVIL ENGINEERING JOURNAL 3-2021

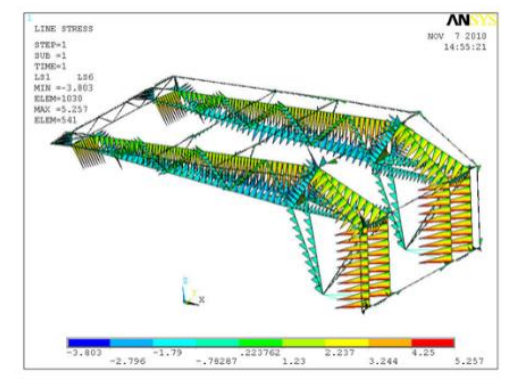

Fig. 11 - Axial stress distribution diagram

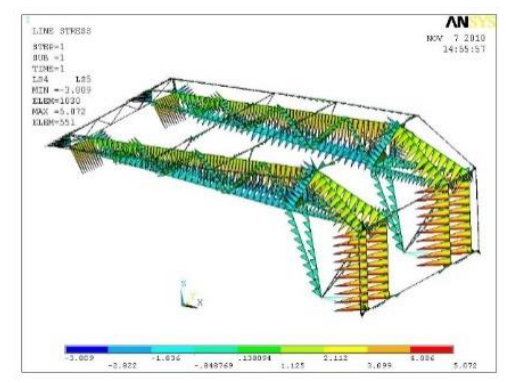

Fig. 12 - Distribution of bending stress

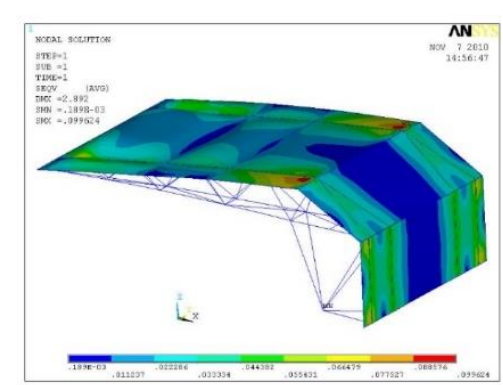

Fig. 13 - Equivalent stress distribution diagram

(2) load condition 2: roof dead weight + wind pressure generated by aerodynamic load of first gear wind speed

1) wind load calculation of the cantilevered roof of the stadium

According to equation (2) $w_{h e}=\xi \mu_{h} w_{0}, \xi=1.45+0.40\left[\frac{\bar{v}_{h} T_{1}}{L}-0.73\right]$ can calculate the maximum value of the triangular load on the leading edge of roof surface.

Here

According to modal analysis,

$$
\begin{gathered}
\mu_{h}=1.0 \\
w_{0}=\frac{\bar{v}_{h}^{2}}{1630}=\frac{9^{2}}{1630}=0.05 \mathrm{kN} / \mathrm{m}^{2} \\
T_{1}=\frac{1}{8.1496}=0.123 \mathrm{~s}
\end{gathered}
$$

$$
\begin{gathered}
\xi=1.45+0.40\left[\frac{\bar{v}_{h} T_{1}}{L}-0.73\right]=1.45+0.40\left[\frac{9 \times 0.123}{0.6}-0.73\right]=1.896 \\
\therefore w_{h e}=\xi \mu_{h} w_{0}=1.896 \times 1.0 \times 0.05=0.095 \mathrm{kN} / \mathrm{m}^{2}
\end{gathered}
$$

2) wind load calculation of column enclosure structure

According to the code for load of building structures GB50009-2012, when calculating the envelope, the standard value of wind load can be calculated according to the following formula

$$
w_{k}=\beta_{g z} \mu_{s} \mu_{z} w_{0}
$$

Where, $\mu_{s}$ is the wind load carrier shape coefficient; $\mu_{z}$ is the change coefficient of wind pressure height; $\beta_{g z}$ is the gust coefficient at height $z$,and $w_{0}$ is the basic wind pressure.

According to the code for load of building structures, $\mu_{s}=1.8, \mu_{z}=1.0, \beta_{g z}=1.0$

$\therefore w_{k}=1.0 \times 1.8 \times 1.0 \times 0.05=0.09 \mathrm{kN} / \mathrm{m}^{2}$

The displacement diagram, axial stress diagram, bending stress diagram and other effect diagram of the structure under this working condition are shown in Fig. 14 and Fig. 18. 


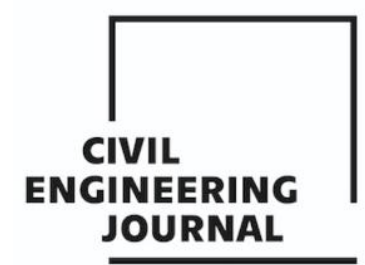

Article no. 52

THE CIVIL ENGINEERING JOURNAL 3-2021

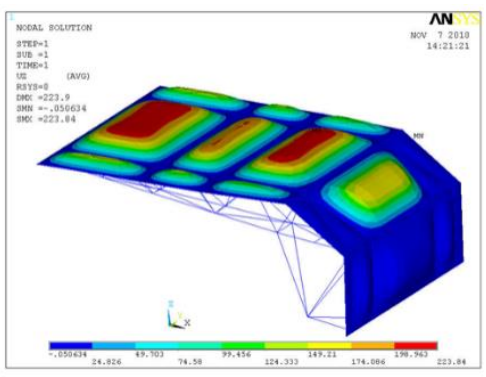

Fig. 14 - Displacement diagram in $\mathrm{Z}$ direction

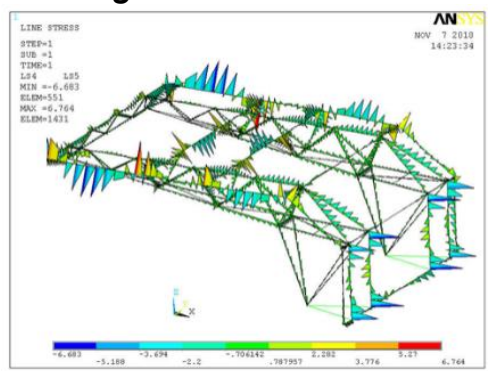

Fig. 17 - Distribution of bending stress

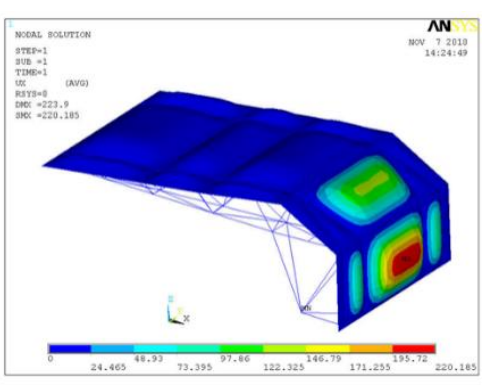

Fig. 15 - Displacement diagram in $\mathrm{X}$ direction

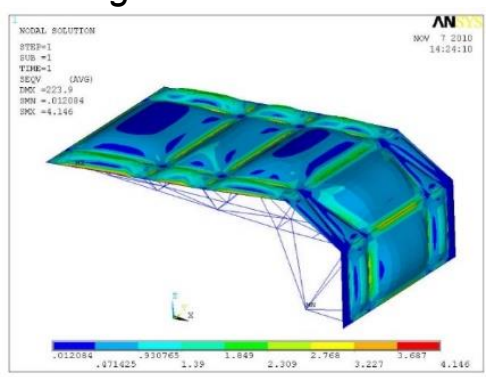

Fig. 18 - Equivalent stress distribution diagram

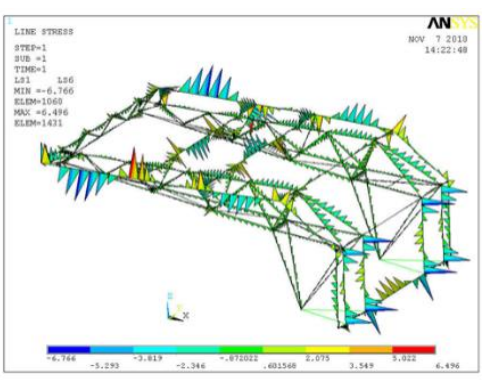

Fig. 16 - Axial stress distribution diagram

(3) load condition 3: roof dead weight + wind pressure generated by aerodynamic load of second gear wind speed

According to equations (2) and (3),

$$
\begin{gathered}
w_{h e}=0.189 \mathrm{kN} / \mathrm{m}^{2} \\
w_{k}=0.158 \mathrm{kN} / \mathrm{m}^{2}
\end{gathered}
$$

The displacement diagram, axial stress diagram and bending stress diagram of the structure under this working condition are shown in Figures 19-23.

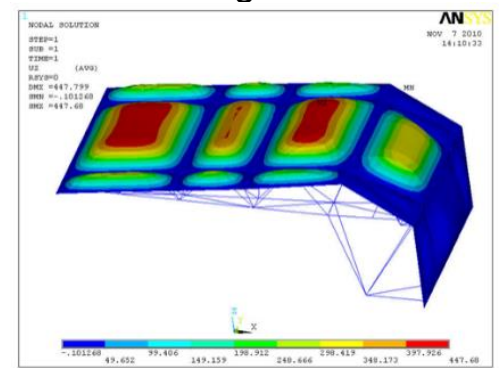

Fig. 19 - Displacement diagram in $\mathbf{Z}$ direction

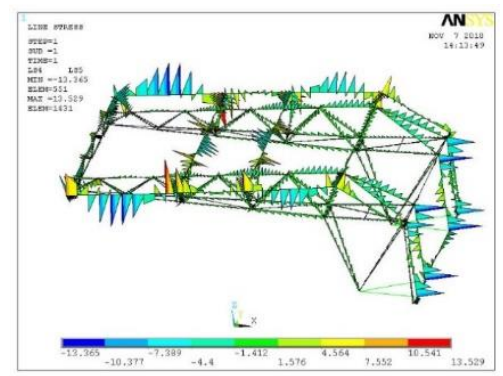

Fig. 22 - Distribution of bending stress

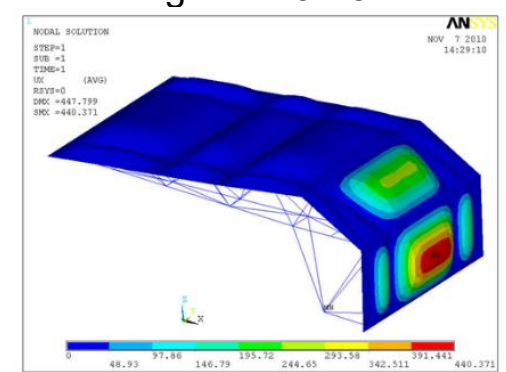

Fig. 20 - Displacement diagram in $\mathrm{X}$ direction

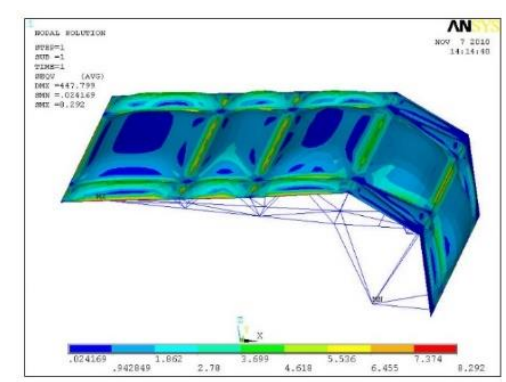

Fig. 23 - Equivalent stress distribution diagram

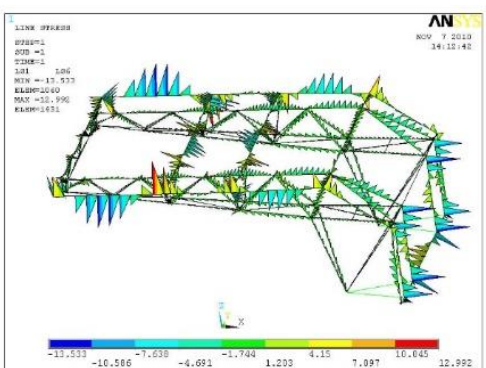

Fig. 21 - Axial stress distribution diagram 


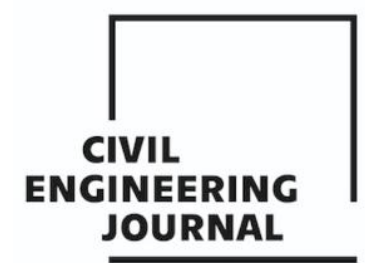

Article no. 52

THE CIVIL ENGINEERING JOURNAL 3-2021

The analysis results of load conditions 1, 2 and 3 are shown in Table 4:

Tab. 4: Analysis results of load conditions 1, 2 and 3

\begin{tabular}{|c|c|c|c|}
\hline \multirow{2}{*}{ Stress or displacement } & \multicolumn{3}{|c|}{ Load condition } \\
\cline { 2 - 4 } & 1 & 2 & 3 \\
\hline Maximum axial stress(MPa) & 5.257 & 6.496 & 12.992 \\
\hline minimum axial stress(MPa) & -3.803 & -6.766 & -13.533 \\
\hline maximum bending stress (MPa) & 5.082 & 6.764 & 13.519 \\
\hline minimum bending stress $(\mathrm{MPa})$ & -3.809 & -6.683 & -13.365 \\
\hline maximum displacement $(\mathrm{mm})$ & 2.892 & 223.9 & 447.799 \\
\hline
\end{tabular}

As can be seen from Table 4, when working under condition 1, the maximum displacement of the cantilevered roof is $2.892 \mathrm{~mm}$, indicating that the roof structure has a relatively high stiffness and the section selection is reasonable. The overall stiffness of the structure is greatly improved by the diaphragm effect of the cloth paper, but the displacement is different from that measured by the test. When working under conditions 2 and 3 , the maximum displacement is up to $223.6 \mathrm{~mm}$ and $447.799 \mathrm{~mm}$, which is quite different from the test results. The main reason is that the flexural stiffness outside the cloth paper plane is not considered, and the finite element model itself is different from the actual one to some extent. It can also be seen from the Tab that the internal forces of the bar meet the requirements.

\section{MODAL ANALYSIS OF THE MODEL}

The frequencies of each order of the structure are shown in Table 5. The modes of the first five orders, seventh order, tenth order, fourteenth order and the twentieth order are shown in Figures 2432.

Tab. 5 - Natural frequencies of each order

\begin{tabular}{|c|c|c|c|c|c|c|c|c|c|c|}
\hline Order number & 1 & 2 & 3 & 4 & 5 & 6 & 7 & 8 & 9 & 10 \\
\hline Frequency & 8.149 & 8.292 & 8.432 & 8.587 & 8.633 & 8.670 & 9.028 & 9.101 & 9.124 & 9.207 \\
\hline
\end{tabular}

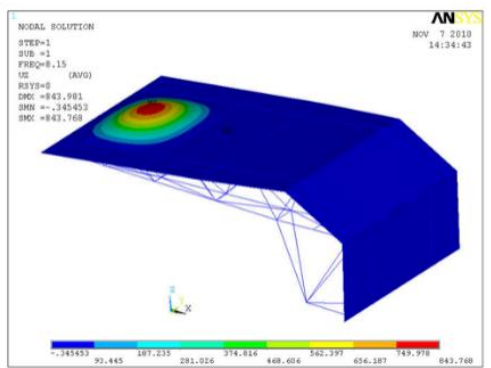

Fig. 24 - Mode 1

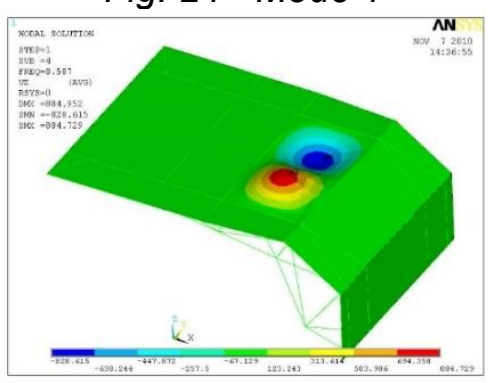

Fig. 27- Mode 4

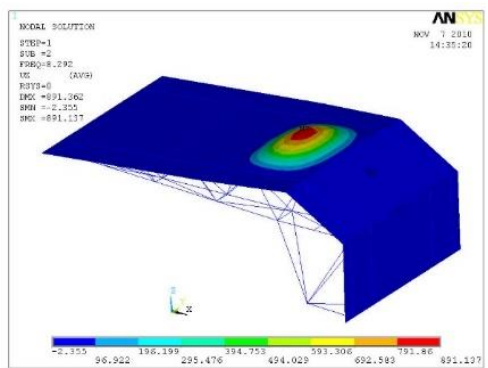

Fig. 25 - Mode 2

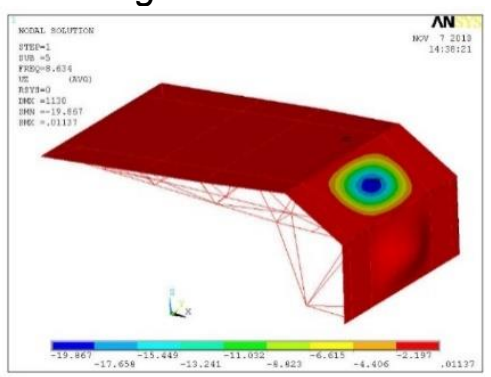

Fig. 28 - Mode 5

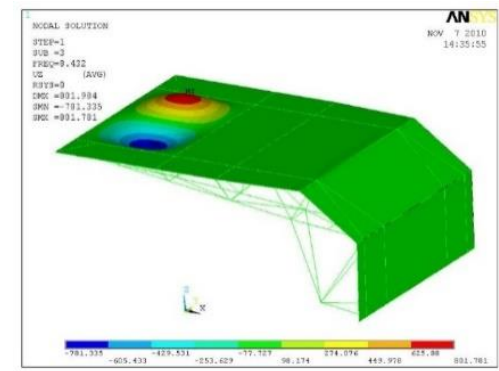

Fig. 26 - Mode 3

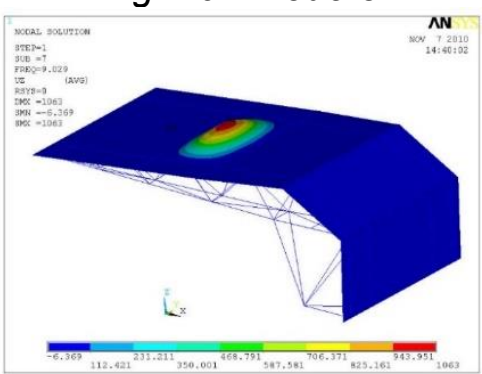

Fig. 29 - Mode 7 


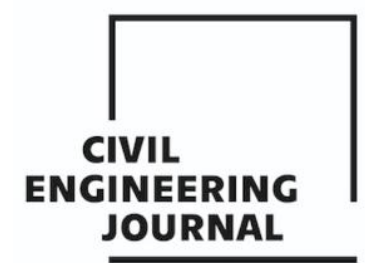

Article no. 52

THE CIVIL ENGINEERING JOURNAL 3-2021

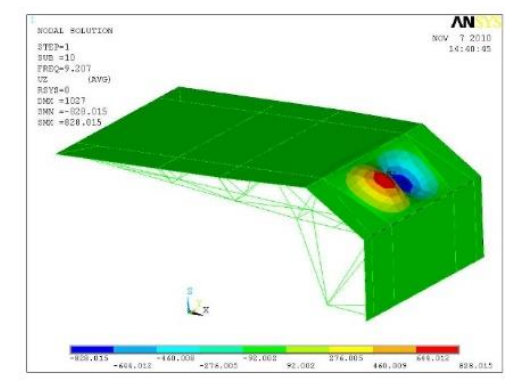

Fig. 30 - Mode 10

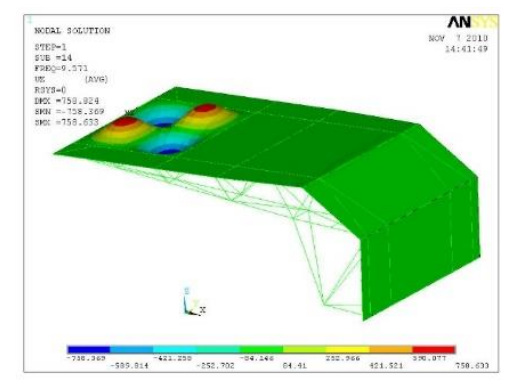

Fig. 31 - Mode 14

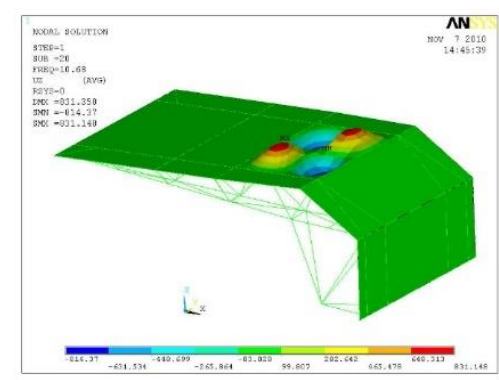

Fig. 32 - Mode 20

\section{CONCLUSION}

Through the analysis of the cantilever roof structure in the upper part of the stadium stand, the following conclusions can be drawn:

(1) There are still some differences in the force analysis and test results of the structure under different load conditions, mainly because the bending stiffness outside the cloth paper plane and the difference between the finite element model and the actual structure are not considered.

(2) It can be seen from Table 5 and the modal analysis of the vibration pattern diagram that the cantilever roof model of the stadium has a dense distribution of vibration modes of all orders, which is mainly local vibration of the structure, indicating that the model does not play a good role in spatial integrity. This is mainly because the bending stiffness outside the cloth paper plane is not considered. During the model design and production, the local enhancement of the low-order mode should be carried out to ensure the overall stability of the structure.

\section{ACKNOWLEDGEMENTS}

This work described in this paper was supported by the Natural Science Basic Research Plan in Shaanxi Province of China (Grant Nos. 2020JQ-917), and Key Curriculum Construction Project of Xi'an Eurasia University (Grant no. 2019KC007).

\section{REFERENCES}

[1] Zhou Yu, research on the selection and application of roof structure of large-space architecture-a swimming pool in Hefei as an example [D]. Huai Nai: Anhui University of Science and Technology,2018.

[2] Hu jing, research on the damping effect of restrained buckling support in floor spherical reticulated shell [D]. Zhou: Lanzhou university of technology, 2008.

[3] Zhang Xue-an Shui-fu Chen. wind load calculation of the stadium stands cantilever roof [J]. Low temperature of architectural technology, 2006, 3:48-50.

[4] Chen Fubin, large-span structure wind effect of in-situ test and wind tunnel test and theoretical analysis research [D]. Changsha: hunan university, 2011.

[5] Shen Qinghua, Dong-ming Zheng, the wind-induced vibration of roof structure analysis [J]. Journal of foreign building materials science and technology, 2008, 29(3): 57-59.

[6] Zhang Xue-an, structure wind load research on the stadium stands cantilever roof [D]. Hangzhou: Zhejiang University, 2006.

[7] Wang Ying, wind load numerical simulation study on large-span space structure [D]. Tianjin: Tianjin University, 2012.

[8] Xiao-kang Li, Zhuang-ning Xie, wind vibration response of long-span roof structures and the fast algorithm and the application of equivalent calm wind load [J]. Journal of civil engineering, 2010, 43 (7) 29-36. 